\title{
Environmental factors associated with acute diarrhea among children under five years of age in derashe district, Southern Ethiopia
}

\author{
Wanzahun Godana ${ }^{1}$, Bezatu Mengiste ${ }^{2}$ \\ ${ }^{1}$ Department of Public Health, College of Medicine and Health Sciences, Arba Minch University, Arba Minch, Ethiopia \\ ${ }^{2}$ Schools of Public Health, College of Health Sciences, Haramaya University, Harar, Ethiopia
}

\section{Email address:}

Wanzanati2011@gmail.com(W. Godana)

\section{To cite this article:}

Wanzahun Godana, Bezatu Mengiste. Environmental Factors Associated with Acute Diarrhea among Children Under Five Years of Age in Derashe District, Southern Ethiopia. Science Journal of public Healh, Vol. 1, No. 3, 2013, pp. 119-124.

doi: $10.11648 /$ j.sjph.20130103.12

\begin{abstract}
Background: Diarrhea alone kills more children than AIDS, malaria, and measles combined. Knowing the determinants of a disease enables us to design an effective intervention. Objective: To identify the factors associated with acute diarrhea among Children less than five Years of Age in Derashe district, south Ethiopia. Methods: A community based unmatched case-control study was employed in rural kebeles of the district. The collected data were entered in Epi Info version3.5.3. Data analyses were done using SPSS for windows version 16.0. Descriptive analysis was used to describe the data. Binary logistic regression analysis was used to measure the association between the dependent variable and independent variables calculating odds ratio and its $95 \%$ confidence interval (CI). Statistical significance was set at $\alpha$. $\leq$ 0.05 . Multivariable analyses were applied to identify the relative effect of explanatory variables on the dependent variable. Results: The study revealed that the occurrence of diarrhea was significantly associated with the lack of latrine ownership (AOR: 2.43, CI:1.19-4.87), lack of home based water treatment (AOR: 2.25, CI:1.43-3.56) improper disposal of infant feces [AOR:3.35, 95\% CI (1.45-4.13)]and lack of improved water sources (AOR: 1.98, CI:1.16- 2.23).Conclusions and recommendation: The determinants of acute diarrhea in this study were that of high preventive value; latrine ownership, availability of home based water treatment and source of water. The authors of the study recommend health education on different mechanisms in diarrheal disease causation and prevention methods.
\end{abstract}

Keywords: Acute Diarrhea, Case-Control Study, Environmental Factors, Water Treatment

\section{Introduction}

Diarrhoea is a major health problem [1]. Diarrhoea is usually a symptom of an infection in the intestinal tract, which can be caused by a variety of causative agents. These causative agents include viruses, bacteria and parasites [2, 3]. Diarrhoeal infection spreads through contaminated food or drinking-water, or from person-to-person as a result of poor hygiene. There are three clinical types of diarrhoea: acute watery diarrhoea - lasts several hours or days, and includes cholera; acute bloody diarrhoea - also called dysentery; and persistent diarrhoea that - lasts 14 days or longer $[1,4]$.

The vast majority of these deaths from diarrheoa are among children under-five years of age living in low- and middle- income countries [5]. Diarrhoeal disease due to unsafe water and lack of sanitation is the biggest cause of morbidity and mortality in under-five children in the world especially in poor countries [5,6]. A child dies every 15 seconds from diarrhoea caused largely by poor sanitation and contaminated water supply [7]. As immune systems are progressively compromised with each bout of diarrhoea; related illnesses indirectly kill millions more. In developing countries, about 2 million people - the vast majority children under-five - die from diarrhoea each year [6]. Nearly $90 \%$ of diarrhoea is attributed to unsafe drinking water, inadequate sanitation and poor hygiene [6].

It is widely recognized that exposure to diarrhoea pathogens in developing countries is associated with such factors as age of the child, quality and quantity of water, availability of toilet facilities, housing conditions, level of education, household economic status, place of residence, feeding practices, and the general sanitary conditions 
(personal or domestic hygiene) around the house [8, 9, 10, 16, 17]. Socioeconomic factors may affect, directly and indirectly, environmental, behavioral, nutritional, and demographic risk factors, with the exception of age and sex [9].

Diarrhoea alone kills more children than AIDS, malaria, and measles combined [10]. Recent estimates indicate that the two-week period prevalence of diarrhoea in under-five children in Ethiopia is about 24 percent [11]. Morbidity-Mortality-and Treatment (MMT) surveys conducted in Ethiopia at different times revealed five diarrhoeal episodes per child per year; and the two-week incidence to be $16 \%$. Studies conducted in central rural Ethiopia revealed that diarrhoea is one of the common causes of under-five mortality, accounting for about $8.4 \%$ to $27 \%$ of all deaths [4].

Diarrhoea is also responsible for $25 \%$ to $75 \%$ of all childhood diseases and account for about $14 \%$ of outpatient visits and 16\% hospital admissions in Ethiopia [11]. In addition to the excess mortality and morbidity, diarrhoea predisposes children to malnutrition, which makes children highly susceptible to other infections. This has been found to be a major contributor to illness and death, particularly among children in Sub-Saharan Africa [9, 14]. Behavioral factors associated with acute childhood diarrhoea include lack of hand-washing, poor infant and young child feeding practices and lack of child immunizations [8, 20, 22, 23, 24, 25]. The objective of the study is to identify the environmental determinants of acute childhood diarrhoea which can be modified to improve of child health interventions.

\section{Methods and Materials}

Study area and period: was conducted in rural kebeles of the Derashe district, Segen Area People's Zone, Southern Nations Nationalities and Peoples Region from January to February, 2012. Derashe district is located at $550 \mathrm{Km}$ from Addis Ababa. According to the report from the district, it has a population number estimated to be 119,569 with 1:1 sex ratio. There are 27,860 women in the reproductive age, 18,653 under-five children. Regarding the environmental health conditions of the district; there is $85 \%$ latrine availability, $41.9 \%$ of the population have access to improved water supply.

Study design: Community based unmatched case-control study design conducted. Case selection: A case was defined as a child under-five years of age, resident in Derashe rural area, with a report of diarrhoea by mother and/care taker in the preceding two weeks before the survey.

Control selection: Control was selected as a child under-five years of age without diarrhoea in the preceding two weeks, randomly chosen from the resident population in the rural kebele.

Study population: The study population was children under-five years of age. Children with persistent diarrhoea were excluded from the study.

Sample size: was calculated based on the following assumptions: $\mathrm{P} 1=$ proportion of diseased with disposal of refuse in pit, $\mathrm{P} 2=$ proportion of non-diseased with disposal of refuse in pit. From similar study conducted in Nekemte town, refuse disposal method as main predictor of the outcome (diarrhoea), it was $42.86 \%$ for cases and $61.47 \%$ for control [11]. Therefore:- P1=0.4286, z1=1.96 (95\% CI) and $\mathrm{P} 2=0.6147, \mathrm{z} 2=0.84$ (power of $80 \%$ ) the proportion of case and control was assumed to be 1:2 With design effect of 2 and $10 \%$ non-response rate, the sample was estimated using the Epi Info software. Thus, the total sample size became 612 (cases $=204$ and controls=408) were taken.

Sampling Technique: Multi-stage sampling procedure was employed, first by selecting five kebeles from the fifteen using lottery method. Then, all households with under-five children in the selected kebeles were registered through a house-to-house survey by ten trained enumerators to register all under-five children with diarrhoea or without diarrhoea. After identifying cases and controls by the census, cases and controls were selected by using a simple random sampling technique.

\subsection{Study Variables}

The dependant variable of the study was the occurrence of acute diarrhoea. Independent variables included socioeconomic and demographic characteristics such as income of a family, maternal age, age of child, housing condition, family size, and maternal education. Environmental factors were: the availability of latrine and utilization, waste disposal, types of water source.

Data Collection Methods: Data were collected from the study population using a pre- tested structured questionnaire through face to face interviews in the local language.

Data Quality Assurance: Properly designed and pre-tested questionnaire was used. Interviewers and data clerks were trained and closely supervised during data collection and entry; and double data entry was used to ensure data quality.

Data Analysis: The data were entered into a pre-drafted coding sheet on Epi info software, version 3.5.3.by two different data clerks. Binary logistic analysis with conditional method calculating odds ratios (OR) and 95\% confidence intervals (CI) was used to estimate the association between the dependent variable and independent variables. Statistical significance was set at $\alpha$. $\leq 0.05$. In an attempt to identify the relative effects of explanatory variables on the outcome variable, hierarchical multivariable analyses was applied. Explanatory variables with $\mathrm{P}$-value $<0.2$ were entered into the final regression model based on the likelihood ratio for further analyses in two different models. 


\subsection{Ethical Approval}

The ethical approval and clearance for this research study was obtained from Haramaya University College of Health Sciences Institutional Research Ethics Review Committee. At all levels, officials were contacted and permission from administrators was secured. All the necessary explanation about the purpose of the study and its procedures was explained with the assurance of confidentiality. Both written and verbal consent from the study participants was also secured.

\section{Results}

\subsection{Socio-Economic and Demographic Characteristics}

A total of 199 cases and 393 controls with response rate of $96.7 \%$ households with children under the age of five years were included in the study. The remaining 20(3.3\%), [ 5 cases and 15 control] households with children under the age of five years were non-respondents because of unavailability. Four hundred eighty seven $(82.3 \%)$ interviews were conducted with mothers and care takers of children under -five years of age and the rest with caretakers.

The occurrence of acute childhood diarrhoea had statistically significant association with the number of under-five children in the household (OR: 1.96, CI: 1.04-3.57), the occupation of the mother (OR: $0.47, \mathrm{CI}$ : $0.31-0.69$ ), and the income of the family (OR: 5.89 , CI (3.97-8.77). Educational status of mothers or care takers, age of index child and ethnicity had no statistically significant association with acute childhood diarrhoea (Table 1).

Table 1. Socio Demographic And Economic Characteristics Of Study Participants, Derashe District, South Ethiopia, 2012.

\begin{tabular}{|c|c|c|c|c|c|}
\hline \multicolumn{2}{|c|}{ Characteristics } & \multicolumn{3}{|c|}{ Cases Controls COR (95\% CI) } & \multirow[t]{2}{*}{ P-value } \\
\hline Family size & $3-5$ & 56 & 138 & 1.00 & \\
\hline & $6-8$ & 97 & 183 & $1.29(0.86-1.96)$ & 0.18 \\
\hline & $9-11$ & 39 & 54 & $1.37(0.82-2.27)$ & 0.20 \\
\hline & $>=12$ & 7 & 18 & $0.54(0.18-1.54)$ & 0.20 \\
\hline \multirow{3}{*}{$\begin{array}{l}\text { Number of } \\
\text { children }\end{array}$} & 51 & 68 & 166 & 1.00 & \\
\hline & 2 & 110 & 200 & $1.34(0.94-1.93)$ & 0.11 \\
\hline & 3 & 21 & 27 & $1.96(1.04-3.75)$ & 0.04 \\
\hline \multirow{4}{*}{$\begin{array}{l}\text { Age of } \\
\text { child }\end{array}$} & $x<6$ month & 27 & 29 & $0.68(0.313-1.48)$ & 0.33 \\
\hline & 6-11 month & 88 & 197 & $1.42(0.76-2.66)$ & 0.28 \\
\hline & 12-23month & 64 & 129 & $1.28(0.67-2.44)$ & 0.46 \\
\hline & $>24$ month & 19 & 30 & 1.00 & \\
\hline \multirow[t]{3}{*}{$\begin{array}{l}\text { Maternal } \\
\text { education }\end{array}$} & $\begin{array}{l}\text { No forma } \\
\text { education }\end{array}$ & 1160 & 301 & $1.21(0.76-1.94)$ & 0.38 \\
\hline & $1-8$ & 35 & 80 & $1.31(0.36-5.22)$ & 0.45 \\
\hline & $>8$ & 4 & 12 & 1.00 & \\
\hline \multirow{2}{*}{$\begin{array}{l}\text { Maternal } \\
\text { occupation }\end{array}$} & Farmer & 127 & 311 & $0.47(0.31-0.69)$ & 0.000 \\
\hline & Others & 72 & 82 & 1.00 & \\
\hline \multirow{2}{*}{$\begin{array}{l}\text { Paternal } \\
\text { occupation }\end{array}$} & Farmer & 165 & 371 & $0.29(0.16-0.52)$ & 0.000 \\
\hline & Others & 34 & 22 & 1.00 & \\
\hline \multirow[t]{2}{*}{ Income } & $<600$ & 145 & 123 & $5.89(3.97-8.77)$ & 0.000 \\
\hline & $>=600$ & 54 & 270 & 1.00 & \\
\hline
\end{tabular}

\subsection{Environmental Factors Associated With Diarrhoea}

Statistically significant association was found between sources of water $(\mathrm{p}=0.000)$, availability of home based water treatment $(\mathrm{p}=0.003)$, latrine ownership $(\mathrm{p}=0.00)$, patterns of adult member defecation $(\mathrm{p}=0.00)$ and disposal of infant feces $(\mathrm{p}=0.000)$ (Table 2).

Table 2.Environmental Factors Related To Acute Diarrhoea Among Study Participants In Derashe District, South Ethiopia, 2012

\begin{tabular}{|c|c|c|c|c|c|}
\hline \multicolumn{2}{|l|}{ Characteristics } & \multicolumn{2}{|c|}{ Cases Controls } & \multirow{2}{*}{$\frac{\text { COR(95\%CI }}{1.93(1.34-2.77)}$} & \multirow{2}{*}{$\frac{\text { P-value }}{0.000}$} \\
\hline \multirow{2}{*}{ Source of water } & Unimproved & 106 & 146 & & \\
\hline & Improved & 93 & 247 & 1.00 & \\
\hline \multirow{2}{*}{$\begin{array}{l}\text { Pericapita water } \\
\text { consumption }\end{array}$} & $r<=20$ liters & 178 & 357 & $0.85(0.47-1.57)$ & 0.58 \\
\hline & $>20$ liters & 21 & 46 & 1.00 & \\
\hline \multirow{2}{*}{ Treating water } & No & 136 & 219 & $1.72(1.18-2.50)$ & 0.003 \\
\hline & Yes & 63 & 174 & 1.00 & \\
\hline \multirow{2}{*}{ Latrine owned } & No & 68 & 81 & $2.00(1.33-2.94)$ & 0.000 \\
\hline & Yes & 131 & 312 & 1.00 & \\
\hline \multirow{2}{*}{$\begin{array}{c}\text { Adult member } \\
\text { defecation }\end{array}$} & $\begin{array}{c}\text { Open } \\
\text { defecation }\end{array}$ & 101 & 165 & $3.02(1.85-4.94)$ & 0.00 \\
\hline & Latrine & 30 & 148 & 1.00 & \\
\hline \multirow{2}{*}{$\begin{array}{l}\text { Disposing } \\
\text { infant feces }\end{array}$} & Not in larine & 81 & 122 & $2.5(1.61-3.85)$ & 0.000 \\
\hline & In larine & 51 & 191 & 1.00 & \\
\hline \multirow{2}{*}{$\begin{array}{l}\text { Separate house } \\
\text { for domestic } \\
\text { animals }\end{array}$} & No & 35 & 60 & $1.211(0.766-1.914)$ & 0.41 \\
\hline & Yes & 159 & 330 & 1.00 & \\
\hline \multirow[b]{3}{*}{ Waste disposal } & In compound & 145 & 284 & $0.93(0.54-1.59)$ & 0.76 \\
\hline & In field & 27 & 49 & $1.22(0.61-2.48)$ & 0.54 \\
\hline & $\begin{array}{c}\text { Stored } \\
\text { transferred to } \\
\text { pit }\end{array}$ & 27 & 60 & 1.00 & \\
\hline
\end{tabular}

\subsection{Multivariable Analysis}

Hierarchical logistic regression technique was used to assess the relative effect of the explanatory variable on the outcome variable. To avoid an excessive number of variables and unstable estimates in the subsequent model, only variables with a p-value less than 0.20 were kept in the subsequent analyses.

Three nested logistic models were used to estimate the effects of explanatory variable on the outcome variable. Model 1: examines the joint effects of socio- economic and demographic factors; Model 2: socio-demographic factors with $p$-value $<0.20$ in Model 1 and environmental factors.

From the total variables that were entered the multivariable regression, four were found to have significant independent association with the diarrhoea. The odds of developing diarrhoea was 1.98 times higher among children whose family used unimproved water source when compared to children of families who used improved water source [AOR:1.98, 95\% CI (1.16-2.23)]. The odds of developing diarrhoea was 2.25 times higher among children whose families did not treat drinking water when compared to children whose families treated water for drinking [AOR:2.25, 95\% CI (1.43-3.56)]. The odds of developing diarrhoea was 2.43 times higher among children of families who had no latrine when compared to children of families who had latrine [AOR: 2.43, 95\% CI (1.19-4.87)]. Other variable that showed significant 
association was the improper disposal of infant feces. Children whose family improperly dispose infant feces were 3.35 times more likely to have diarrhoea when compared to those children whose family properly dispose infant feces [AOR:3.35, 95\% CI (1.45-4.13)]( table 3).

Table 3. Independent Predictors Of Acute Diarrhoea In Derashe District, South Ethiopia, 2012.

\begin{tabular}{|c|c|c|}
\hline \multirow[t]{2}{*}{ Characteristics } & \multirow[t]{2}{*}{ COR(95\% CI) } & $\operatorname{AOR}(95 \% \mathrm{CI})$ \\
\hline & & Model 2 \\
\hline \multicolumn{3}{|l|}{$\begin{array}{l}\text { Socio-demographic and } \\
\text { economic factors } \\
\text { Family size }\end{array}$} \\
\hline $3-5$ & 1.00 & \\
\hline $6-8$ & $1.29(0.86-1.96) 1.95(0.96-3.96)$ & $0.68(0.37-6.79)$ \\
\hline $9-11$ & $1.37(0.82-2.27) 1.32(0.68-2.55)$ & $0.91(0.53-4.88)$ \\
\hline$>=12$ & $0.54(0.18-1.54) 2.16(0.81-5.72)$ & $1.09(0.24-7.12)$ \\
\hline \multicolumn{3}{|l|}{ Number of U5C } \\
\hline 1 & 1.00 & 1.00 \\
\hline 2 & $1.34(0.94-1.93) 1.42(0.68-2.55)$ & $1.12(0.62-3.89)$ \\
\hline 3 & $1.96(1.04-3.75) 2.61(0.81-5.72)$ & $1.22(0.66-4.93)$ \\
\hline \multicolumn{3}{|l|}{ Maternal occupation } \\
\hline \multicolumn{3}{|l|}{ Paternal occupation } \\
\hline $\begin{array}{l}\text { Farmer/others } * * \\
\text { Income }\end{array}$ & $0.29(0.16-0.52) 0.32(0.03-4.13)$ & $1.12(0.50-2.52)$ \\
\hline, $600 />=600 \mathrm{ETB}^{* *}$ & $5.89(3.97-8.77) 0.99(0.163-6.03)$ & - \\
\hline \multicolumn{3}{|c|}{ Environmental Factors } \\
\hline \multicolumn{3}{|c|}{$\begin{array}{l}\text { Unimproved/improved**1.93(1.34-2.77) } \\
\text { Treating water }\end{array}$} \\
\hline $\mathrm{No} / \mathrm{Yes}^{* *}$ & $1.72(1.18-2.5)$ & $2.22(1.31-3.42)^{*}$ \\
\hline \multicolumn{3}{|l|}{ Latrine owned } \\
\hline No/yes** & $2.00(1.33-2.94)$ & $1.64(1.12-2.41)^{*}$ \\
\hline \multicolumn{3}{|c|}{ Disposing of infant feces } \\
\hline Not in latrine/latrine ${ }^{* *}$ & $2.5(1.61-3.85)$ & $3.35(1.45-4.13)^{*}$ \\
\hline
\end{tabular}

** Reference category, * statistically significant association $(\mathrm{P}<0.05)$

$\mathrm{COR}=$ Crude Odd Ratio, $\mathrm{AOR}=$ Adjusted Odd Ratio

\section{Discussions}

The results of this study indicated that the determinants of acute diarrhoea in this study were source of household water, availability of home-based water treatment, latrine ownership and disposal of infant feces.

Unimproved water source is among the potential sources for diarrhoeal diseases transmission. The probability of contamination of water sources depends on whether or not the source is protected. Households using unprotected water sources were three times more likely to have a child with diarrhoea. This finding is in agreement with another study conducted in Gonder [25]. But, it contradicts with a study conducted in Gojam zone [17]. This might be due to the fact that there might be mixed use of water from both protected and unprotected sources, contamination during transport and storage or lack of homogeneity in source of water in study conducted in Gojam.

Availability of home based drinking water treatment was an independent predictor of diarrhoeal morbidity in this study. Children whose families used home based drinking water treatment such as boiling; chemicals (aqua tabs and wuha-agar) and or filtering were found to have lower odds of getting diarrhoea when compared to children whose families did not use water treatment method. Because collected water is liable for contamination during collection, transportation and storage which may in turn increase risk of diarrhoeal diseases. This finding is in agreement with study in Kenya [18], but contradicts other previous studies in Ethiopia [17]. This difference might be attributed to the various methods of home based water treatment, and difference in the overall sanitation of the environment.

In this study children from households without toilet facilities were more likely to develop diarrhoea compared to children from households with latrine facility. The presence of toilets increases the chance of its utilization which in turn facilitates the safe disposal of feces. This is one way of decreasing contact between causative organisms of diarrhoeal and the host. This finding was similar to other studies $[8,13,14,18,19,21,26]$. Improper disposal of infant feces were strongly associated with acute childhood diarrhea, this was consistent with different previous studies $[8,11,13]$.

It has been documented that there is a high chance of contamination, and greater risk of diarrhoea associated with bottle-feeding. Even though it was not statistically significant in the multivariable analysis, the odds of getting diarrhoea in bottle-fed children was about one and a half times greater than the odds among children who were not bottle-fed. Bottle-feeding was significantly associated with diarrhoeal morbidity in the bivariate analysis. Similar findings were observed in India and Nekemte, western Ethiopia [8].

The number of under-five children and family size were not independently associated with diarrhoeal morbidity. This is in agreement with a study from Jimma [13] but contradicts the finding from Meskanena Mareko Woreda and from Gojam Hullet Ejju Ense woreda where greater family size was associated with diarrhoeal morbidity $(\mathrm{OR}=2.07$ and $\mathrm{OR}=2.3$ respectively $[17,27]$. There might be differences in maternal attention, general living condition and difference in study design that could explain the disparate finding. It is known that as the number of children in a family becomes larger, there may be crowding which deteriorates the hygiene condition, which in turn increases the chance of contact with pathogens. There may also be competition for the mother's attention and other resources.

The strength of this study is that- it was community based and that it particularly addressed acute childhood diarrhoeal morbidity in rural community. Additionally, the study had high response rate $(96.7 \%)$. However, the limitation of the study came from the retrospective design of the study. Since the study is a case-control study, there could be potential for recall bias. This was minimized using reported incident cases within two weeks period.

In conclusion, the factors that were associated with acute childhood diarrhoea in this study were latrine availability, home based water treatment, source of water and disposal 
of infant feces. Very high proportion of the adults of the population used to defecate in open land. This can also increase the risk of diarrhoeal disease. The authors of the study recommend protection of water sources for the community. The community is also advised to treat drinking water to reduce the risk of diarrhoea. Food hygiene and general sanitation is highly recommended and further research: in the area is also recommended.

\section{Acknowledgments}

The authors thanks and acknowledges the Federal Ministry of Education of Ethiopia for funding this research. Special acknowledgement goes to Haramaya University for facilitating the funds from Ministry of Education. Our deep gratitude goes to our data collectors and supervisors and the study community.

\section{Authors' Contributions}

WG conceived of and designed the study, supervised data collection, analyzed the data, drafted the paper and approved the final version and also participated in interpretation of findings, contributed to the drafting of the paper, revising the manuscript critically for intellectual content and up-dated the manuscript. BM contributed to the conception, designing, data analysis, drafting and approval of the manuscript. Both authors read and approved the manuscript.

\section{References}

[1] Kosek, M., C. Bern, and R.L. Guerrant The magnitude of the global burden of dirrhoeal disease from studies published 1992-2000 Bulletin of WHO 2003. 81: p. 197-204.

[2] Pruss-Utun A, Kay D, Fewtrell L, Bartram J. Unsafe water, Sanitation and Hygiene. Comparative qualification of health risks. Geneva; WHO, 2004.p 1321-1351.

[3] Nyantekyi, A., Mengistu, L., Mulugeta, B., Konjit, T., Keberten, M. and Chanda, M. Intestinal parasitic infections among under-five children and maternal awareness about the infections in Shesha Kekele, Wondo Genet, Southern Ethiopia. Ethiopian Journal of Health Development. 2010; 24(3): $185-190$

[4] Shimelis D. Effect of Zinc supplementation in treatment of acute diarrhoea among 2-59 months children treated in Black Lion Hospital, Addis Ababa, Ethiopia. Ethiopian Journal of Health Development. Dec. 2008; 22(2).186-90

[5] USAID. Integrating sanitation and water supply proprams. Anuual report in Africa, 2010.

[6] Jill W, Wenjing, T., Jenny L. and Forsberg B. Diarrhoeal Diseases in Low- and Middle-Income Countries. The Open Infectious Diseases Journal. 2010.4 (123):113-124
[7] Barreto, M., Genser,B., Strina, A., Gloria, T., Marlucia, O., Rita, Rego., Carlos ,Teles., Matildes, S., Prado, M., Matos, A., Santos,D., Cairncross,S.2007. Effect of city-wide sanitation programme on reduction in rate of childhood diarrhoea in northeast Brazil: assessment by two cohort studies. Lancet 2007; 370: 1622-28

[8] Wondwossen B. A stepwise regression analysis on under-five diarrhael morbidity prevalence in Nekemte town, western Ethiopia: Maternal care giving and hygiene behavioral determinants. East African Journal of Public Health Volume 5 Number 3 December 2008.p 193-198.

[9] Green S, Small J, Casman A. Determinants of National Diarrhoeal Disease Burden. Environmental Science \& Technology 2009 vol. 43, no. 4, pp123-31

[10] WHO/ UNICEF. Why children are dying and what to be done? 20 Avenue Appia, 2009,1211 Geneva 27, Switzerland; p12-29

[11] Girma R, Wondwossen B, Bishaw D and Tefera B. Environmental determinants of diarrhoea among under-five children in Nekemte Town, western Ethiopia. Ethiopia Jornal of Health Sciences 2007. 18(2 ): 39-44

[12] Amare D, Fassil T \& Belaineh G. Determinants of under-five mortality in Gilgel Gibe Field Research Center, Southwest Ethiopia. Ethiopian Journal of Health Development. 2007; 21(2):117-124.

[13] Tesfahun A. and Mekasha A .Determinants of diarrhoeal diseases: a community based study in urban south western Ethiopia. East African Medical Journal 2003. Vol. 80 No. 2, $77-82$

[14] Vafaee A, Moradi A, Khabazkhoob M. Case-Control Study of acute diarrhoea in Children: Dept. of Health and Management, School of Health and Paramedical Science, Mashhad University of Medical Science, Iran Journal Research and Health Sciences 2008, Vol. 8, No. 1, pp. 25-32.

[15] Usman A, Rahaem A, Angola B. Exploring the Social and Environmental Determinants of Child Health in Ilorin, Nigeria. Ethiopian Journal of Environmental Studies and Management 2009.Vol.2 No.3,p 73-82

[16] Genser B, Strina A, Teles C, Prado M and Barreto M. Risk factors for acute diarrhoea incidence: dynamic analysis of a longitudinal study, Epidemiology; salvador, Brazil. International Journal of Epidemiology 2006. 17 (6):658-667

[17] Andualem A. Assessment of the impact of latrine utilization on diarrhoeal diseases in the rural community of Hulet Ejju Enessie Woreda, East Gojjam Zone, Amhara Region. Ethiopian Journal of Health Development. 2010; 24(3). $110-18$ 
[18] Fewtrell L, Kaufmann B, Kay D, Enanoria W, Haller L, Colford J. Water, sanitation, and hygiene interventions to reduce diarrhoea in less developed countries. A systematic review and meta-analysis. Lancet Infectious Disease 2005. 5: $42-52$.

[19] Clasen T, Schmidt W, Rable T, Roberts I and Cairncross S. Interventions to improve water quality for preventing diarrhoea: Systematic review and meta-analysis. British medical journal 2007. 334, 782-791.

[20] Bettenheim M. The sanitation environment in urban slums: implications for child health, Popul Environ 2008.30:26-47

[21] Barklay L. Hand-washing can reduce diarrhoea by $30 \%$. Cochrane Database Systematic Review, published document 2008 .

[22] Ehiri E, Ejemot I, Meremikwu M and Critchley A. Hand-washing for preventing diarrhoea. Cochrane database of systematic reviews 2008. (1). Art.No.: CD004265.

[23] Luby S, Halder A, Unicomb T, Huda L and Richard B. The Effect of Handwashing at Recommended Times with Water

\begin{abstract}
Alone and With Soap on Child Diarrhoea in Rural Bangladesh: An Observational Study. Public library of Science Medicine 2011. 8(6): e1001052. doi:10.1371/journal.pmed.1001052.
\end{abstract}

[24] Takanashi K, Chonan Y, Quyen DT, Khan NC, Poudel KC and Jimba M. Survey of food-hygiene practices at home and childhood diarrhoea in Viet Nam. Journal of Health \& Population Nutrition 2009. 27(5):602-611.

[25] Mediratta P, Amsalu F, Lawrence H, Sisay Y and Sack R. Risk Factors and Case Management of Acute Diarrhoea in North Gondar Zone, Ethiopia. Journal of Health Population and Nutrition 2010. 28(3): 253-263

[26] Muluken D. Does the effect of water and sanitation vary by maternal education on childhood diarrhoea among under-five children in Mecha district, west Gojam, Ethiopia. Master thesis, Addis Ababa University, 2009.

[27] Teklu M. Socio-economic, environmental and behavioral factors associated with occurrence of diarrhoea among under-five in Maskenena Mareko woreda, southern Ethiopia. Master thesis, Addis Ababa University, 2003. 